http://sciforum.net/conference/ece-1

Conference Proceedings Paper - Energies ,, Whither Energy Conversion? Present Trends, Current Problems and Realistic Future Solutions”"

\title{
Small-Scale ORC Energy Recovery System for Wasted Heat: Thermodynamic Feasibility Analysis and Preliminary Expander Design
}

\author{
Roberto Capata $^{1}$,Claudia Toro ${ }^{1, *}$ \\ 1 Department of Mechanical and Aerospace Engineering, University of Rome "Sapienza", Via \\ Eudossiana 18, Rome, Italy ; E-Mail: roberto.capata@uniroma1.it; \\ * Author to whom correspondence should be addressed; E-Mail: claudia.toro@uniroma1.it; \\ Tel.: +39-0644585272; Fax: +39-0644585250.
}

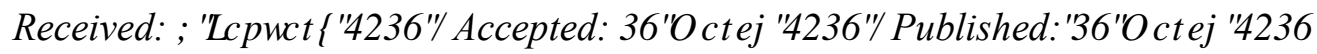

\begin{abstract}
The paper analyses the thermodynamic feasibility of an innovative Organic Rankine Cycle (ORC) recovery system. Among the many applications of this device, particular interest covers the application as bottoming systems for the exploitation of wasted heat from the exhaust gases of an ordinary ICE. The vehicle thermal source can be either a typical diesel engine $(1400 \mathrm{cc})$ or a small gas turbine set $(15-30 \mathrm{~kW})$. The sensible heat recovered from the exhaust gases feeds the energy recovery system that can produce sufficient extra power to sustain the conditioning system and other auxiliaries. The concept is suitable for all types of thermally propelled vehicles, but it is studied here for automotive applications. The characteristics of the organic cycle-based recovery system are discussed, and a preliminary design of the main component, such as expander is presented. The main challenge are the imposed size and weight limitations that require a particular design. A possible system layout is analyzed and the requirements for a prototypal application are investigated.
\end{abstract}

Keywords: ORC energy recovery system; R245fa; components design; system simulation.

\section{Introduction}

In a context where energy resources are even more expensive and rare and the pollution is one of the most important issues, the researchers try to increase the efficiencies of energy conversion systems 
to reduce the emissions and the fuel consumption. For example internal combustion engines (ICE), commonly used for automotive and often for electrical generation, are characterized by an average efficiency of $35 \%$. It means that two third of the energy is wasted during the cycle. The energy recovery could be a good way to increase the overall efficiency of such systems. The system can be considered as a combined cycle where the heat of the exhaust gases is the "fuel" of the bottoming system. This approach is general and it is possible, theoretically, to couple a bottoming system to every cycle having a discharging temperature higher than the environment one. However if the temperature of the exhaust gases is not sufficiently high it is not possible to use a common Rankine Cycle (RC) as bottoming system, because the efficiency will be too much low. The limit of Rankine Cycle for this application is not determined by the technology, the main problems are related to the proprieties of the the working fluid, water. For these applications, it is more convenient to use organic fluids, commonly used in the refrigerant cycles. A Rankine Cycle operating with such fluids is called Organic Rankine Cycle (ORC). In the most simple configuration, an ORC is composed, generally, by an heat recovery steam generator, an expander to recover energy from the fluid, a condenser where the fluid condensates and a pump. The cycle is obviously closed because the organic fluids are expensive and they cannot be discharged in the environment.

The Organic Rankine Cycles could be applied to many low-temperature heat sources, such as geothermic, solar, biomass or heat recovery from combustion. The configuration of the cycle could be change to obtain the optimal efficiency for the actual application and for the size of the plant.

As analyzed by [1] several studies and applications of Organic Rankine Cycle (ORC) systems for recovering waste heat con be found in literature. There is a wide range of heat sources which can be applied to the ORC systems such as waste heat from the condenser of a conventional or a nuclear power plant [2], waste heat from industrial processes [3,4], solar radiation [5], and geothermal energy [6].

In [7] the potential improvement of the overall efficiency of a heavy-duty truck diesel engine equipped with an ORC bottoming cycle is investigated .

In this work a small-scale ORC energy recovery system fed by the exhaust gases of the diesel engine or GT device has been considered and analyzed

Actually small size plants are considered too much expensive and ORC with a power less than $10 \mathrm{~kW}$ are uncommon.

The aim of this paper is to verify the thermodynamic feasibility of the proposed system and to start a preliminary design of the expander at this small scale. The novelty lies in this component (dynamic expander instead a common scroll or screw expander) and its application as a system of heat recovery from exhaust gas. To illustrate the design procedure, it was necessary to briefly describe the fluid operating and architecture of our system. Once the structure and the layout of the ORC have established. the simulation was carried out. This simulation data were input data for the expander preliminary design.

\section{Organic fluids}

The first step was, therefore, to choose the working fluid. After various tests, which were not reported, but that were made in previous papers [8], has been chosen the fluid: R245fa. 
It is considered need to supply a small description about this type of fluid and their peculiar characteristics.

Compared to water, organic fluids present interesting thermodynamic properties for heat recovery from low temperature sources:

1. a lower vaporization heat;

2. a lower vaporization temperature at the same pressure than water;

3. some of them have a positive slope of the saturation vapor curve;

4. an high heat capacity due to their molecular length.

First three properties allow to use low temperature sources, the fourth consents to have an expansion from a non-superheated vapor point without enter in the vapor dome. This aspect is fundamental, because is not necessary to superheat the fluid because at the end of the expansion the fluid is still in the vapor (Fig. 1 and Fig. 2) phase avoiding any problems in the expander, especially if it is a turbine.

Some authors [9] list their properties and the best applications in terms of expander type and temperature source; others researchers [10] screens 20 different organic fluids for exhaust heat recovery of an Internal Combustion Engine. In theory, the first step in an ORC design is the choice of the fluid based on the source; in practice, most used fluids are three:

1. R134a (1,1,1,2-Tetrafluoroethane)

2. R123 (2,2-Dichloro-1,1,1-trifluoroethane)

3. R245fa (1,1,1,3,3-Pentafluoropropane)

In addition to the thermodynamically properties, the organic fluids for ORC have to be secure for people and environment:

1. No flammable

2. No explosive

3. Non-toxic

4. Low Ozone Depletion Potential (ODP)

5. Low Global Warming Potential (GWP)

Figure 1. thermodynamic characteristics for an organic fluid

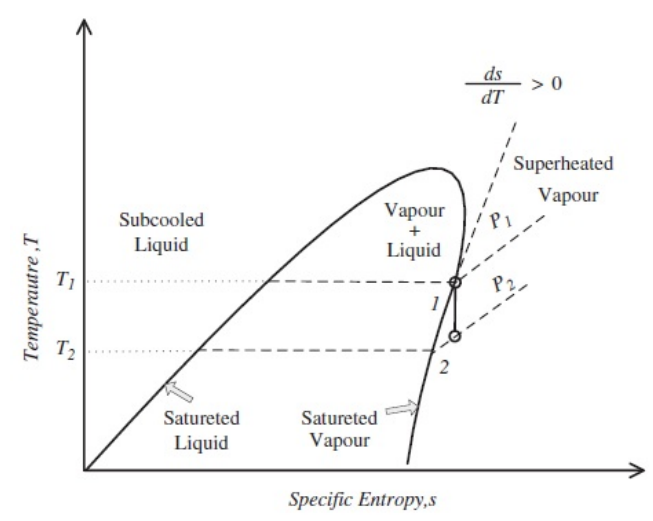


Figure 2. Comparison between water and an organic fluid phase-change characteristics during heat exchange
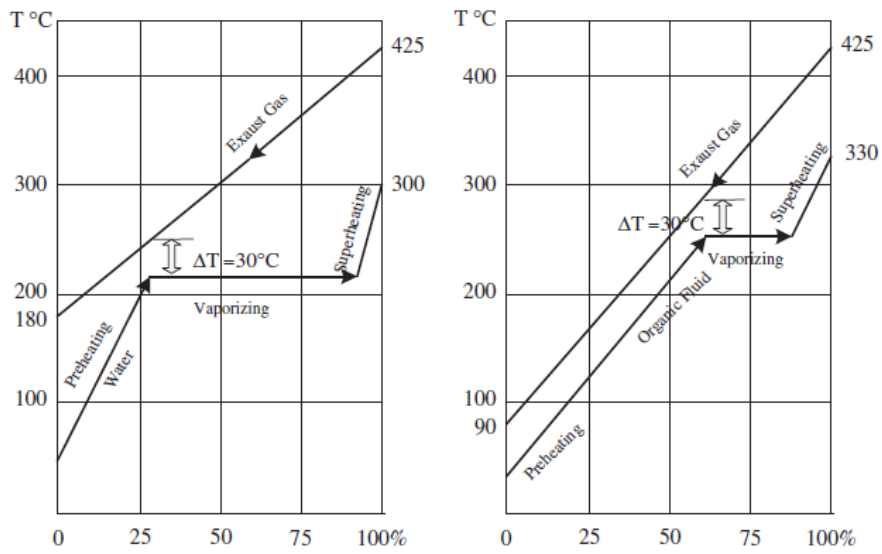

\section{$2.1 R 245 f a$}

The 1,1,1,3,3-Pentafluoropropane, also named as R245fa, is an hydrofluorocarbon, is common in ORC applications, thanks to the following properties:

1. A positive slope of the saturated vapour curve

2. No superheating needed

Safety properties:

1. It doesn't damage the ozone layer

2. It's nearly non-toxic

3. No degradation at the temperature of the cycle [11]

Figure 3: R245fa Pressure-Enthalpy diagram

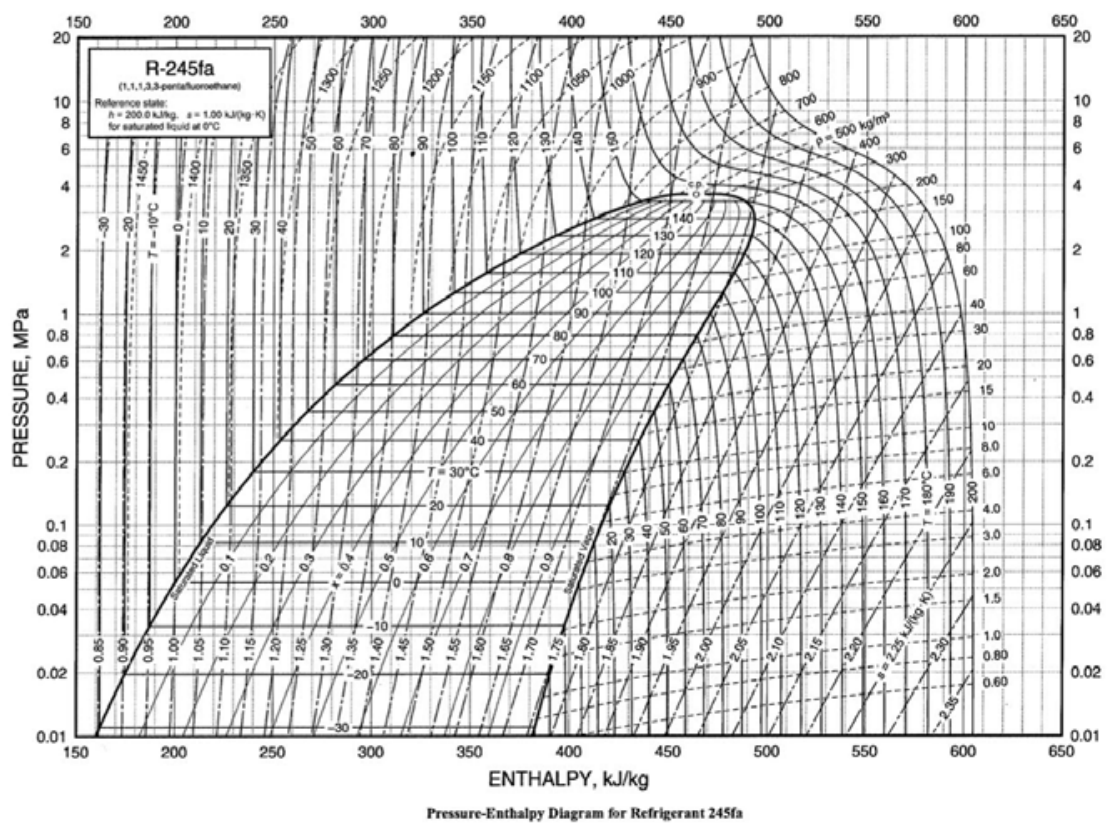


Table 1. R245fa properties [11]

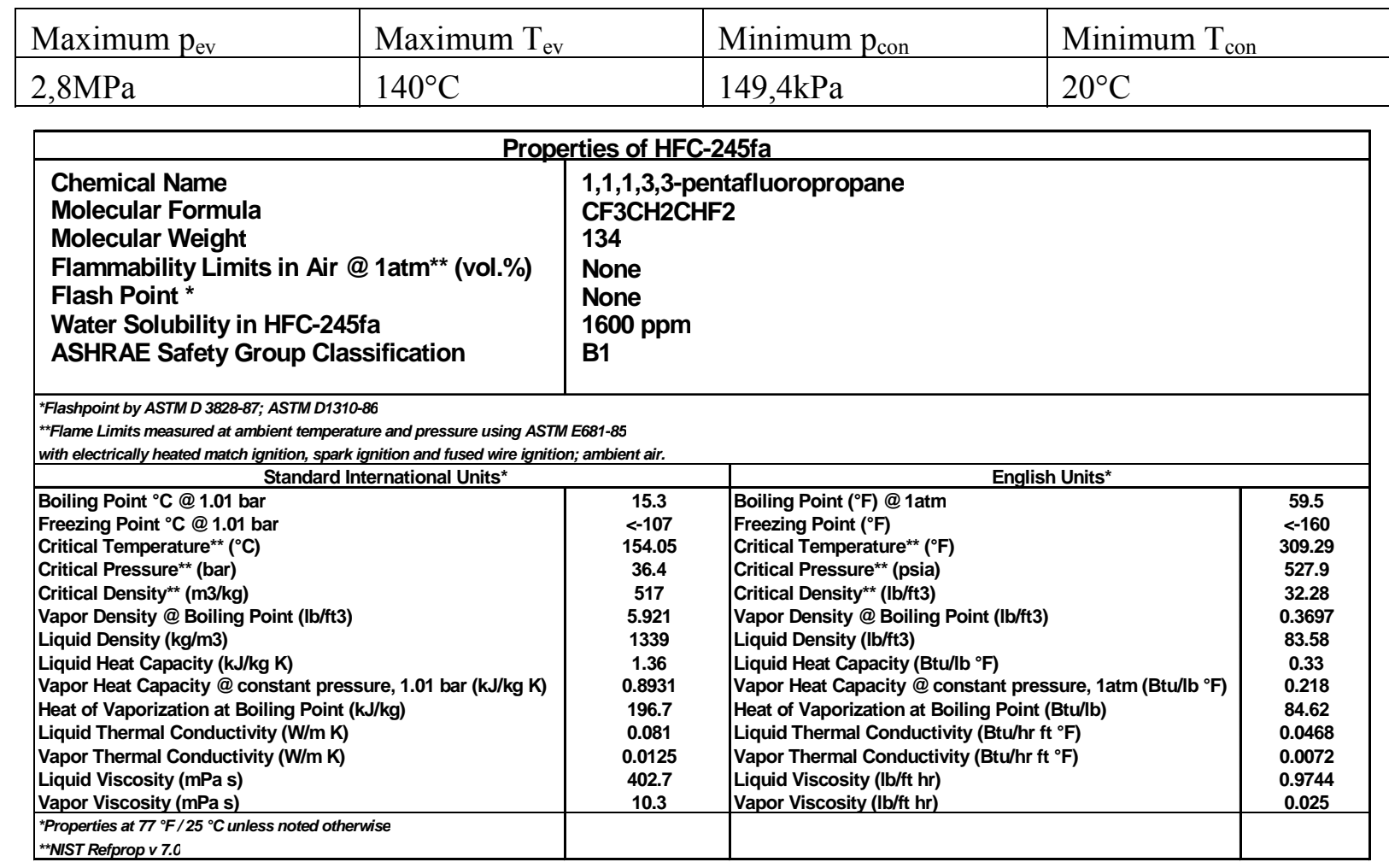

The main properties of the $\mathrm{R} 245 \mathrm{fa}$ are reported in Table 1 and its pressure-enthalpy diagram is shown in Fig.3

The properties of the organic fluids influence the design of the expander, especially if it is a radial turbine.

One of the limit in the radial turbines is the Mach number. The big molar mass and the low temperature give a lower speed of sound than steam water, thus the velocities must be lower to have a subsonic flow and avoiding additional shock losses.

Since the density of organic fluids are larger than water, the overall dimensions of the turbine are smaller.

The low nominal power of the plant, the small flow rate and the high pressure ratio lead to choose a single-stage radial turbine. To design the expander, it is necessary to evaluate the operative condition of the turbine, in terms of temperature and pressure, by means a process simulator.

\section{Objective of the study}


As previously described, the purpose of the paper is to design the expander. In usual practice, this component a scroll or a screw ones. In this case, we tried to see the feasibility of using a dynamic expander. In order to complete this procedure, it was needed to briefly describe other types of machine. In fact, the expander is the fundamental component of the ORC and several types of expander are used:

- Turbines

- Scroll expanders

- Screw expanders

Turbines are not very suitable for ORC especially for small-scale plants, but they have the advantage of small dimensions [12]. A thermo-fluid dynamics design of turbo-expanders for ORC is presented in [13]

Volumetric machines remain the best choice.

Scroll expanders (Fig. 4) are developed from scroll compressors operating in an expander mode. In last years many researchers have evaluated their performance and probably they are the best choice for small-scale applications[14].

Figure 4. Scroll expander and Screw expander
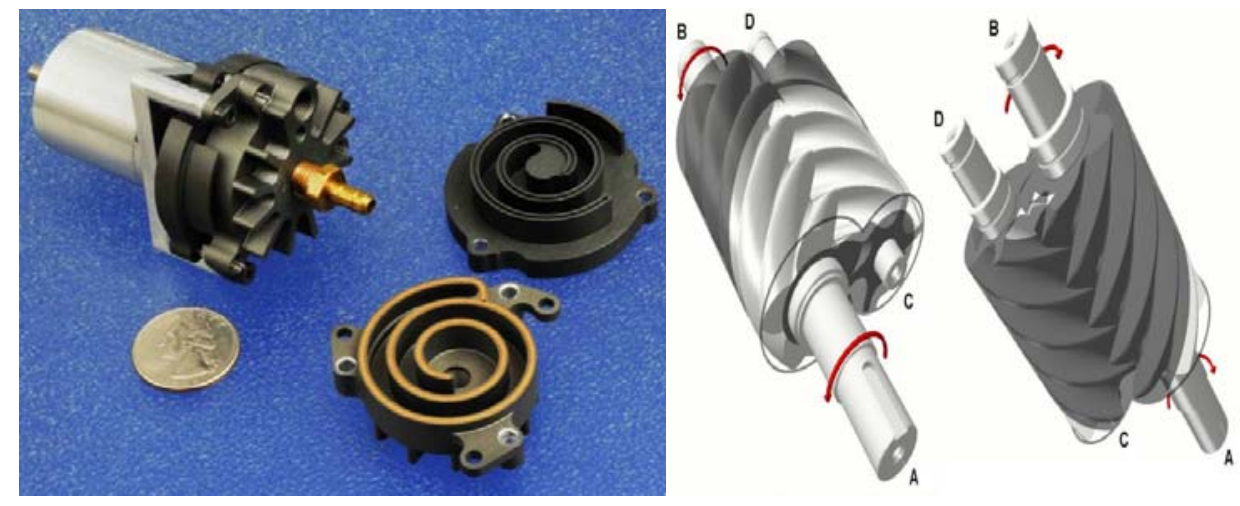

Screw expanders (Fig. 4) have the advantage of a simple architecture and they can achieve an outlet power above $20 \mathrm{~kW}[15]$.

Despite these considerations, we had to notice that the aim of this paper, is to evaluate the feasibility to design, and eventually build, a dynamic expander.

The paper is focused on the design of a small-scale ORC radial turbine for energy recovery from the exhaust gas of a Diesel engine using R245fa as working fluid. The request power of the system is 5 $\mathrm{kW}$ with an available exhaust gas flow rate of $0.16 \mathrm{~kg} / \mathrm{s}$ at $848 \mathrm{~K}$. This temperature is high for a typical ORC application, especially for the required low power; this means that the energy content is too high and probably the use of Rankine Cycle instead an ORC would be more efficient, nevertheless for a compact application an organic fluid is more convenient, because the dimensions of the heat exchangers are smaller. 


\section{Thermodynamic simulation}

The thermodynamic simulation of the ORC cycle was performed by CAMEL-Pro ${ }^{\mathrm{TM}}$ process simulator, a software developed at the Mechanical Engineering Department of the University of Rome "Sapienza"[16]. Since the power is not high, it is not convenient to design a sophisticated cycle with preheaters or re-heaters commonly used in large-size plant. Thus, the cycle is very simple and only few components are required (Fig. 5):

1. Air Heat Recovery: it is a heat exchanger where the organic fluid warms up and changes its phase from liquid to vapor. This transformation is considered isobaric and in the phase changing is also isothermal.

2. Steam Turbine: it operates between the pressure imposed upstream and downstream by the heat recovery and the condenser.

3. Condenser: used to condensate the organic fluid with water. This transformation is considered isobaric and also isothermal during the phase changing.

4. Pump: it increases the pressure of the organic fluid, now liquid, up to the pressure inside the Air Heat Recovery.

5. Flow Mixer: necessary to add the possible make up flow rate.

From the statement of the problem, the input constrains are:

The output power from the turbine (flow 6): $5 \mathrm{~kW}$

The available mass flow rate of the exhaust gas (flows 3 and 4): $0,16 \mathrm{~m}^{3} / \mathrm{s}$

Temperature of the exhaust gas (flows 3 and 4): $848 \mathrm{~K}$

Figure 5. ORC Plant layout in CAMEL-Pro ${ }^{\mathrm{TM}}$

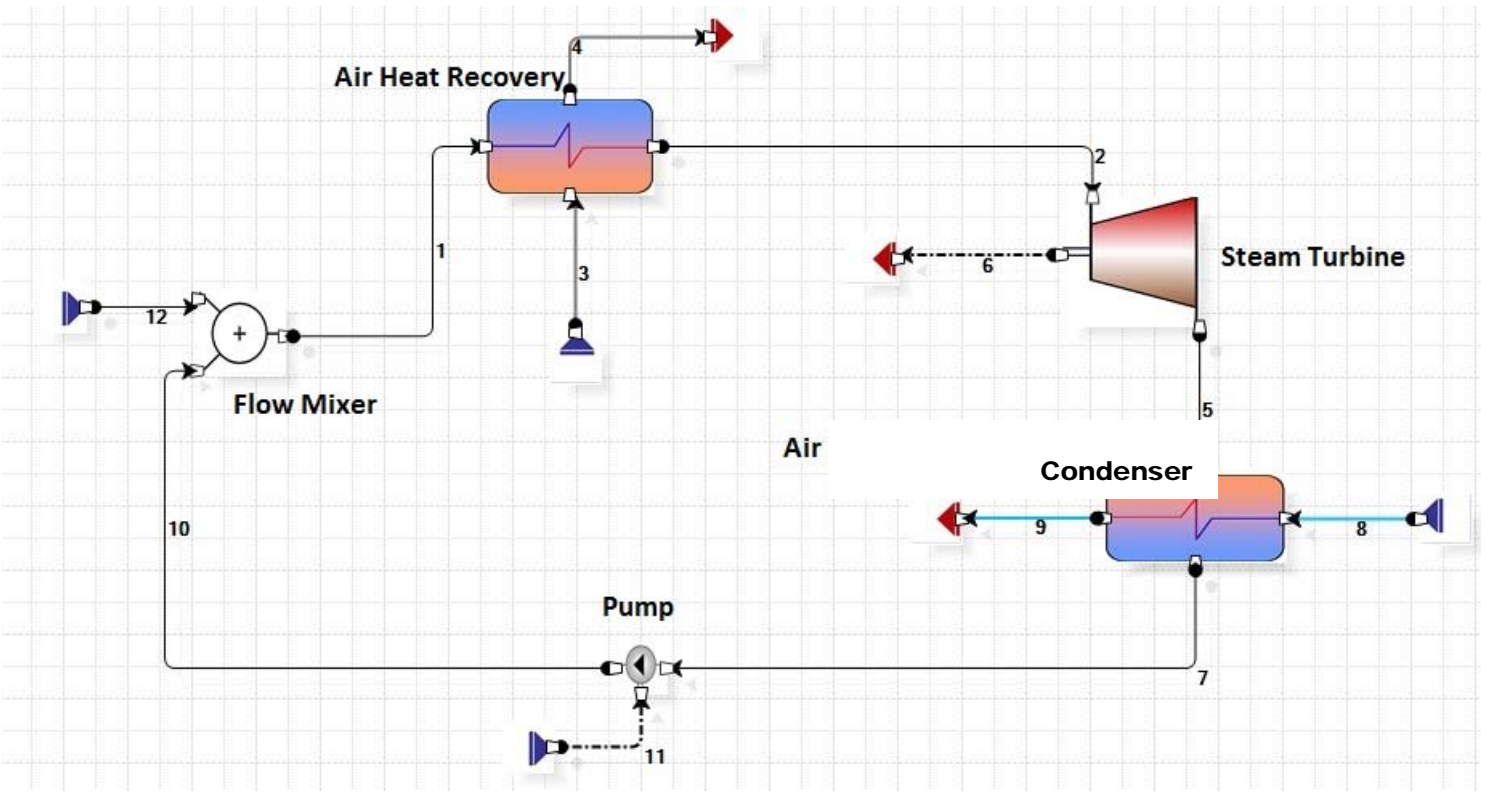

The temperature of the inlet water is set to $293 \mathrm{~K}$, hence, considering the finite dimensions of the condenser and its losses, the organic fluid should condense at $301 \mathrm{~K}$, because it cannot reach lower 
temperature. Thanks to the thermodynamics properties, setting the condensation temperature means that the condensation pressure is fixed. From the thermodynamics tables for R245fa [11], this fluid condenses at $301 \mathrm{~K}$ with a pressure of $170 \mathrm{kPa}$. Since the expander is a single-stage turbine, it has a limit in the pressure ratio, for this reason the upstream pressure is fixed too.

Analyzing the very few models available a $\beta=3,2$ has been considered which means a $p_{\text {upstream }}=$ $550 \mathrm{kPa}$.

The turbine adiabatic efficiency has been underrated at $\eta_{\mathrm{ad}}=0.75$ to be sure that the outlet power was at least $5 \mathrm{~kW}$ and the efficiency of the pump is fixed to 0,9 .

The results obtained by the process simulation are reported in Table 2 .

Table 2 The state properties of the computed ORC cycle

\begin{tabular}{cccccc}
\hline Working Fluid & \multicolumn{4}{c}{ R245fa } \\
\hline State & $m$ & $p$ & $T$ & $h$ & $s$ \\
\hline & & & & & \\
2 & 0.293 & 550 & 301 & -187.2 & -0.656 \\
5 & 0.293 & 550 & 358 & 49.1 & 0.04 \\
7 & 0.293 & 170 & 334 & 31.6 & 0.06 \\
10 & 0.293 & 170 & 301 & -187.5 & -0.656 \\
& 0.293 & 550 & 301 & -187.2 & -0.65 \\
\hline
\end{tabular}

\section{Proposed expander design method}

The procedure adopted to design the radial turbine is based on Harold Rohlik study [17]. In this study five specific losses for various combination of stator exit flow angle $\alpha_{1}$ are calculated and the outlet to inlet diameter ratio $d_{2} / d_{1}$, and the ratio of stator blade height to rotor exit diameter $b_{1} / d_{2}$ are then extrapolated.

The three independent variable from which started Rohlik optimization procedure are:

$$
\begin{aligned}
& 52^{\circ}<\alpha_{1}<83^{\circ} \\
& 0.04<\mathrm{h}_{1} / \mathrm{D}_{2, \mathrm{~m}}<0.68 \\
& 0.2<\mathrm{D}_{2, \mathrm{~m}} / \mathrm{D} 1<0.6
\end{aligned}
$$

Rohlik defined the following state (Fig. 6): 0 stator inlet, 1 rotor inlet and 2 rotor outlet. The angle $\alpha_{1}$ is the complementary angle formed by the direction of $U$ and $V$ in the velocity triangle. $h_{1}$ is the height of the rotor blade, $\mathrm{D}_{2 \mathrm{~m}}$ diameter of the midspan section at the exit of the rotor and, finally, $\mathrm{D}_{1}$ is the diameter at the rotor inlet. 
Figure 6: Reference turbine configuration in Rohlik method

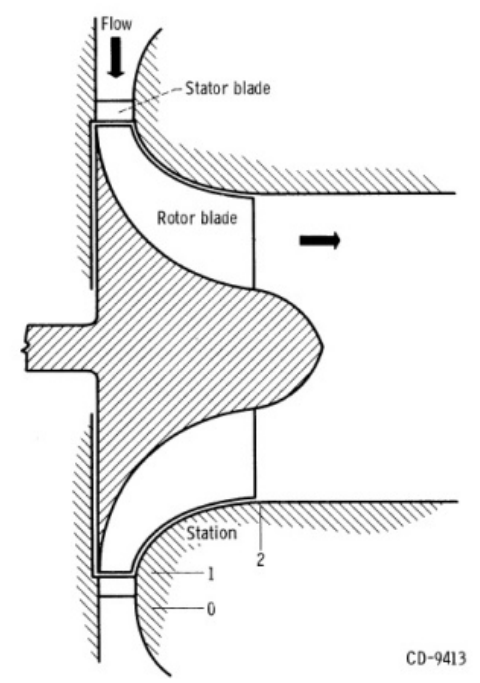

The losses considered are stator loss, rotor loss, tip-clearance loss, windage and exit kinetic energy. According to these calculation, Rohlik developed some charts that show optimal geometric and kinematic parameters for every specific speed $n_{s}$.

$n_{s}$. is expressed through the three independent variables :

$$
\mathrm{n}_{\mathrm{S}}=\frac{60 *(2 \mathrm{~g})^{3 / 4}}{\sqrt{\pi}} *\left(\frac{\Delta \mathrm{h}}{\Delta \mathrm{h}^{\prime}}\right)^{3 / 4} *\left(\frac{\mathrm{u}_{1}}{\mathrm{~V}_{\mathrm{j}}}\right)^{3 / 2} *\left(\frac{\mathrm{V}_{2}}{\mathrm{u}_{2}}\right)^{1 / 2} *\left(\frac{\mathrm{D}_{2, \mathrm{~m}}}{\mathrm{D}_{1}}\right)^{3 / 2} *\left(\frac{\mathrm{b}_{1}}{\mathrm{D}_{2, \mathrm{~m}}}\right)^{\frac{1}{2}}
$$

The charts reported in Fig. 7, developed by Rohlik, were used in our work in order to choose and verify the optimal geometric and kinematic ratio of the machine. This charts permit the systematic selection of optimum turbine size and shape for a variety of turbine application.

Figure 7: Rohlik chart for blade design [17]
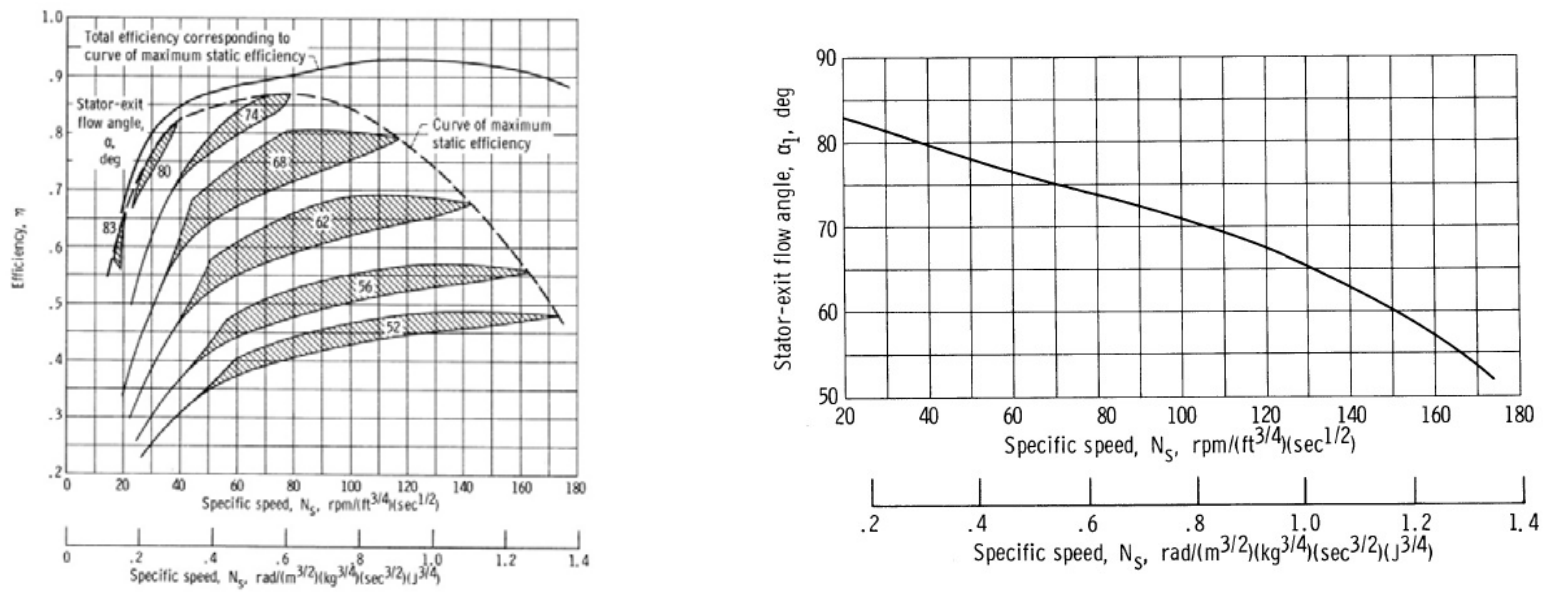
Figure 7 shows the optimal (in term to static and total efficiency) angle $\alpha_{1}$, as a function of specific speed. It can be notice in Fig. 8 that Rohlik angles are complementary to ours one.

Figure 8: Rohlik angles

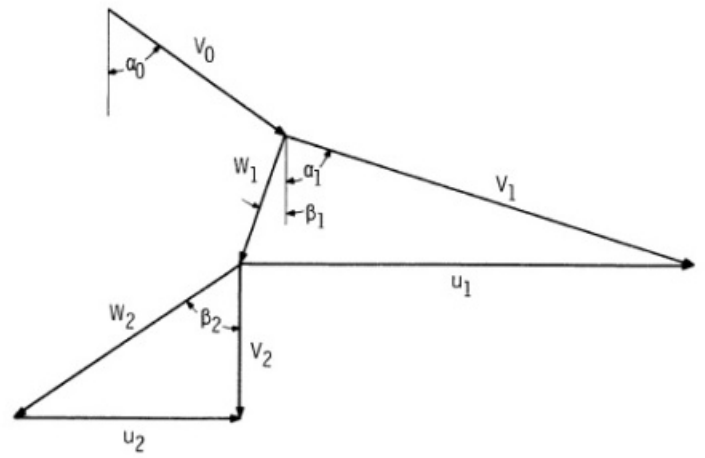

Figure 9: The ns vs $b_{1} / D_{1}$ and $n s$ vs $D_{2 e} / D_{1}$ chart used by Rohlik [17]
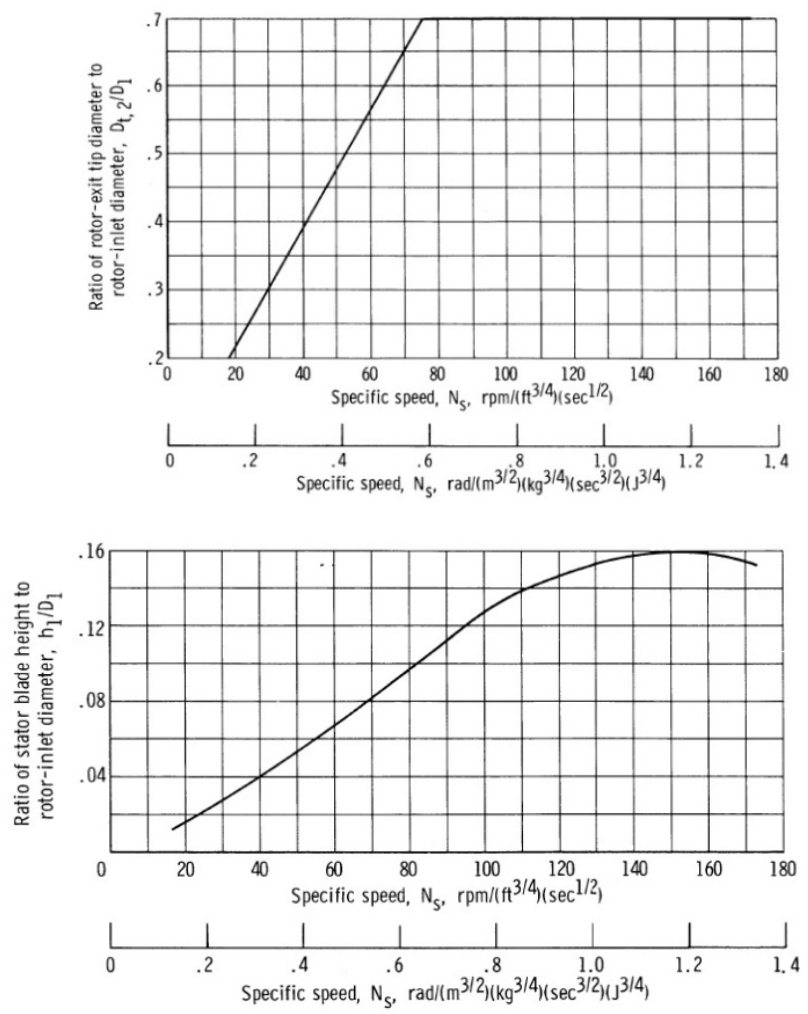

Moreover, the charts reported in Fig. 9 show the optimal trend, as a function of specific speed, of the ratio of the stator blade height to rotor inlet diameter $b_{1} / D_{1}$ and the ratio of rotor exit tip diameter to rotor inlet diameter $\mathrm{D}_{2 \mathrm{e}} / \mathrm{D}_{1}$.

There is an upper limit on $\mathrm{D}_{2 \mathrm{e}} / \mathrm{D}_{1}$ which must not exceed 0,7. Finally, Rohlik also presented three optimum turbines (Fig. 10) sections geometry, that correspond to the curve of maximum static efficiency at three values of specific speed. 
Figure 10: Optimum turbine geometry by Rohlik [17]

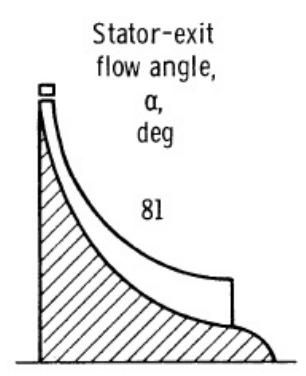

(a) Specific speed, $30 \mathrm{rpm}$ per foot ${ }^{3 / 4}$ per second $1 / 2$ $\left(0.23 \mathrm{rad} /\left(\mathrm{m}^{3 / 2}\right)\left(\mathrm{kg}^{3 / 4}\right)\right.$ $\left.\left(\sec ^{3 / 2}\right)\left(\mathrm{J}^{3 / 4}\right)\right)$; blade-jet speed ratio, 0.68 .

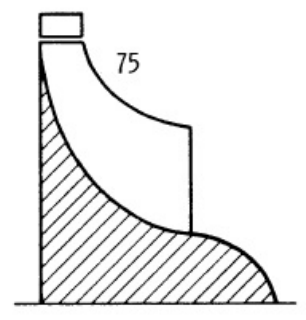

(b) Specific speed, $70 \mathrm{rpm}$ per foot $3 / 4$ per secondl $1 / 2$ $\left(0.54 \mathrm{rad} /\left(\mathrm{m}^{3 / 2}\right)\left(\mathrm{kg}^{3 / 4}\right)\right.$ $\left.\left(\sec ^{3 / 2}\right)(\mathrm{J} 3 / 4)\right)$; blade- et speed ratio, 0.70 .

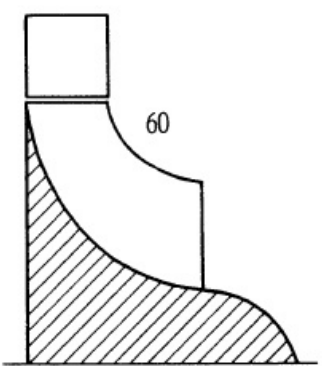

(c) Specific speed, $150 \mathrm{rpm}$ per foot $3 / 4$ per secondl $/ 2$ $\left(1.16 \mathrm{rad} /\left(\mathrm{m}^{3 / 2}\right)\left(\mathrm{kg}^{3 / 4}\right)\right.$ $\left.\left(\sec ^{3 / 2}\right)\left(\mathrm{J}^{3 / 4}\right)\right)$; blade-jet speed ratio, 0.62 .

\section{Preliminary design of radial turbine for ORC}

As reported in the previous the process simulator gave us all state properties of the ORC cycle (pressure, temperature and enthalpy at inlet and outlet turbine sections), the Euler's work and the mass flow rate evolving in machine.

Setting the degree of reaction $\mathrm{R}_{\rho}$ at 0.5 , pressure, enthalpy, temperature and, consequently, density at rotor inlet section have been calculated.

Table 3: Thermodynamic conditions

\begin{tabular}{lll}
\multicolumn{3}{c}{ Simulation results $\boldsymbol{\beta}=\mathbf{3 . 2}$} \\
\hline $\mathbf{m}$ & 0,29 & $\mathrm{~kg} / \mathrm{s}$ \\
$\mathbf{h}_{\mathbf{0}}$ & 49088 & $\mathrm{~J} / \mathrm{kg}$ \\
$\mathbf{h}_{\mathbf{2}}$ & 31678 & $\mathrm{~J} / \mathrm{kg}$ \\
$\mathbf{p}_{\mathbf{0}}$ & 5,5 & $\mathrm{bar}$ \\
$\mathbf{p}_{\mathbf{2}}$ & 1,7 & $\mathrm{bar}$ \\
$\mathbf{T}_{\mathbf{0}}$ & 358 & $\mathrm{~K}$ \\
$\mathbf{T}_{\mathbf{2}}$ & 334 & $\mathrm{~K}$ \\
$\mathbf{L}_{\mathbf{e}}$ & 17241 & $(\mathrm{~m} / \mathrm{s})^{2}$ \\
$\boldsymbol{\rho}_{\mathbf{0}}$ & 27,76 & $\mathrm{~kg} / \mathrm{m}^{3}$ \\
$\boldsymbol{\rho}_{\mathbf{2}}$ & 8,6 & $\mathrm{~kg} / \mathrm{m}^{3}$ \\
\hline
\end{tabular}

Table 4: Rotor inlet conditions Rotor Inlet $\boldsymbol{\beta}=\mathbf{3 . 2}$

$\begin{array}{lll}\mathbf{h}_{1} & 40298 \quad \mathrm{~J} / \mathrm{kg}\end{array}$

$\begin{array}{lll}\mathbf{p}_{1} & 3,5 & \text { bar }\end{array}$ 


\begin{tabular}{lll}
\hline $\boldsymbol{T}_{1}$ & 344 & $\mathrm{~K}$ \\
$\boldsymbol{\rho}_{1}$ & 17,8 & $\mathrm{~kg} / \mathrm{m}^{3}$ \\
\hline
\end{tabular}

The equation set is:

$$
\begin{aligned}
& Q_{1}=\frac{m}{\rho_{1}}=\pi D_{1}^{2} b_{1} U_{1} \varphi_{1} \delta_{p 1} \\
& Q_{2}=\frac{m}{\rho_{2}}=\pi \frac{D_{2 e}^{2}}{4}\left(1-\chi^{2}\right) U_{2} \varphi_{2} \delta_{p 2} \\
& L_{E}=U_{1}^{2} \psi_{1}^{2} \\
& U_{1}=\frac{\omega D_{1}}{2} \\
& U_{2}=\frac{\omega D_{2}}{2} \\
& \rho=F(p, T) \\
& \frac{p_{2}}{p_{0}}=\left(\frac{T_{2}}{T_{0}}\right) \\
& w_{2}<0.9 \mathrm{C}_{\mathrm{s} 2} \\
& \psi_{2}=0 \\
& \mathrm{U}<\mathrm{U}_{\max } \\
& \delta_{p 1}=\delta_{p 2}=0.9
\end{aligned}
$$

There are five degrees of freedom in the design procedure. Setting $\psi_{2}=0$, in order to optimize Euler work, and $\mathrm{R}_{\mathrm{p}}=0.5$, that means $\psi_{1}=1$ and radial blade at the rotor inlet because of structural reason and in order to optimize efficiency leading to Chen and Baines chart, has been calculated the blade speed:

$$
\mathrm{U}_{1}=\sqrt{\frac{\mathrm{L}_{\mathrm{E}}}{\psi_{1}}}
$$

The value of $\mathrm{U}_{1}$ respects the condition $\mathrm{U} / \mathrm{V}_{\mathrm{s}}=0.7$, where $\mathrm{V}_{\mathrm{s}}=\sqrt{2 \mathrm{~L}_{\mathrm{E}}}$.

To limit the machine overall dimensions, the rotor inlet diameter $\mathrm{D}_{1}$ has been set at $0.1 \mathrm{~m}$. Then the rotational speed has been found:

$$
\omega=\frac{2 \mathrm{U}_{1}}{\mathrm{D}_{1}}=2626 \mathrm{rad} / \mathrm{s}=418 \mathrm{~s}-1=25090 \mathrm{rpm}
$$

From these results, $n_{s}$ and $d_{s}$ has been calculated, 0.3 and 6.2 respectively, and from Balje's chart we found an efficiency of about 0.83 , that is acceptable.

\subsection{Inlet section}

$\psi_{1}$, D1 and U1 are known. $\psi_{1}=1$ so $\mathrm{V} 1 \mathrm{t}=\mathrm{U} 1$ and we calculated the magnitude of $\mathrm{V} 1$ taking the value of $\alpha 1=10^{\circ}$, with $n s=0.3$ from Rohlik's diagram. Then, w1 $=\mathrm{V} 1 \mathrm{~m}$ and 1 has been found and the velocity triangle at the inlet is completely defined. Finally the inlet blade height b1 has been 
calculated from the continuity equation. The b1/D1 ratio is close to the optimal region from Rohlik's chart and the sonic limitations: $\mathrm{V} 1<0.93 \mathrm{Cs} 1$ is respected (where Cs1 $=142 \mathrm{~m} / \mathrm{s}$ from tables) The inlet section kinematic and geometry values are reported in the table 5

Table 5: Inlet section

\begin{tabular}{cccc}
\hline $\mathbf{D}_{\mathbf{1}}[\mathbf{m}]$ & 0.1 & $\mathbf{U}_{\mathbf{1}}[\mathbf{m}]$ & 131 \\
$\left(\mathbf{9 0}-\right.$ Rohlik) [ $\left.{ }^{\circ}\right]$ & 10 & $\mathbf{V}_{\mathbf{1 t}}[\mathbf{m}]$ & 131 \\
$\varphi_{\mathbf{1}}$ & 0.18 & $\mathbf{W}_{\mathbf{1}}[\mathbf{m}]$ & 23 \\
$\boldsymbol{\psi}_{\mathbf{1}}$ & 1 & $\mathbf{V}_{\mathbf{1}}[\mathbf{m}]$ & 133 \\
$\mathbf{b}_{\mathbf{1}}[\mathbf{m}]$ & 0.0025 & $\mathbf{V}_{\mathbf{1 m}}[\mathbf{m}]$ & 23 \\
$\mathbf{b}_{\mathbf{1}} / \mathbf{D}_{\mathbf{1}}$ & 0.025 & $\mathbf{M a}_{\mathbf{1 v}}$ & 0.9 \\
& & $\boldsymbol{\beta}_{\mathbf{1}}\left[^{\circ}\right]$ & 90 \\
\hline
\end{tabular}

\subsection{Outlet section}

It has been set $\varphi_{\mathrm{cb}}=\varphi_{2} \frac{\mathrm{D}_{2}}{\mathrm{D}_{1}}=0.25$ from Chen and Baines chart and $\frac{\mathrm{D}_{2, \mathrm{~m}}}{\mathrm{D}_{1}}=0.4$ from Rholik's study, $\varphi_{2}$ and $D_{2, m}$ has been found. Consequently, U2,m and V2m are known and, knowing that $\mathrm{V} 2 \mathrm{t}=0$, relative speed $\mathrm{w} 2 \mathrm{~m}$ has been calculated.

Table 6: Outlet section

\begin{tabular}{lclc}
\hline$\varphi_{\mathbf{c}}$ & 0.25 & $\mathbf{V}_{\mathbf{2 m}}[\mathbf{m} / \mathbf{s}]$ & 32 \\
$\mathbf{D}_{\mathbf{2 m}} / \mathbf{D}_{\mathbf{1}}$ & 0.4 & $\mathbf{U}_{\mathbf{2 m}}[\mathbf{m}]$ & 52 \\
$\mathbf{D}_{\mathbf{2}}[\mathbf{m}]$ & 0.04 & $\mathbf{W}_{\mathbf{2 m}}[\mathbf{m}]$ & 62 \\
$\mathbf{D}_{2 \mathrm{i}}[\mathbf{m}]$ & 0.031 & $\boldsymbol{\beta}_{\mathbf{2}}\left[^{\circ}\right]$ & 32 \\
$\mathbf{D}_{\mathbf{2}}[\mathbf{m}]$ & 0.049 & $\boldsymbol{\varphi}_{\mathbf{2}}$ & 0.63 \\
$\mathbf{D}_{\mathbf{2}} / \mathbf{D}_{\mathbf{1}}$ & 0.5 & $\boldsymbol{\psi}_{\mathbf{2}}$ & 0 \\
$\mathbf{b}_{\mathbf{2}}[\mathbf{m}]$ & 0.0091 & $\chi_{\mathbf{2}}$ & 0.6 \\
& & & \\
\hline
\end{tabular}

The velocity triangle on the mean line is completely defined. From the continuity equation, $\mathrm{D}_{2 \mathrm{i}}$ has been found and consequently $\mathrm{D}_{2 \mathrm{e}}$ and $\chi=\frac{D_{2 i}}{D_{2 e}}$ are known. Finally, it have to verify if Rolhik limits have been respected:

$$
\begin{aligned}
& \chi \geq 0.4 \\
& \mathrm{D}_{2 \mathrm{e}} / \mathrm{D}_{1 \leq 0.7} 0.7
\end{aligned}
$$

These results, about sonic limitation of choking, are acceptable and the choking in the rotor is avoid. 
In Fi. 11 the velocity triangles at inlet and outlet section are shown.

Figure 11: Blade shape and velocity triangles

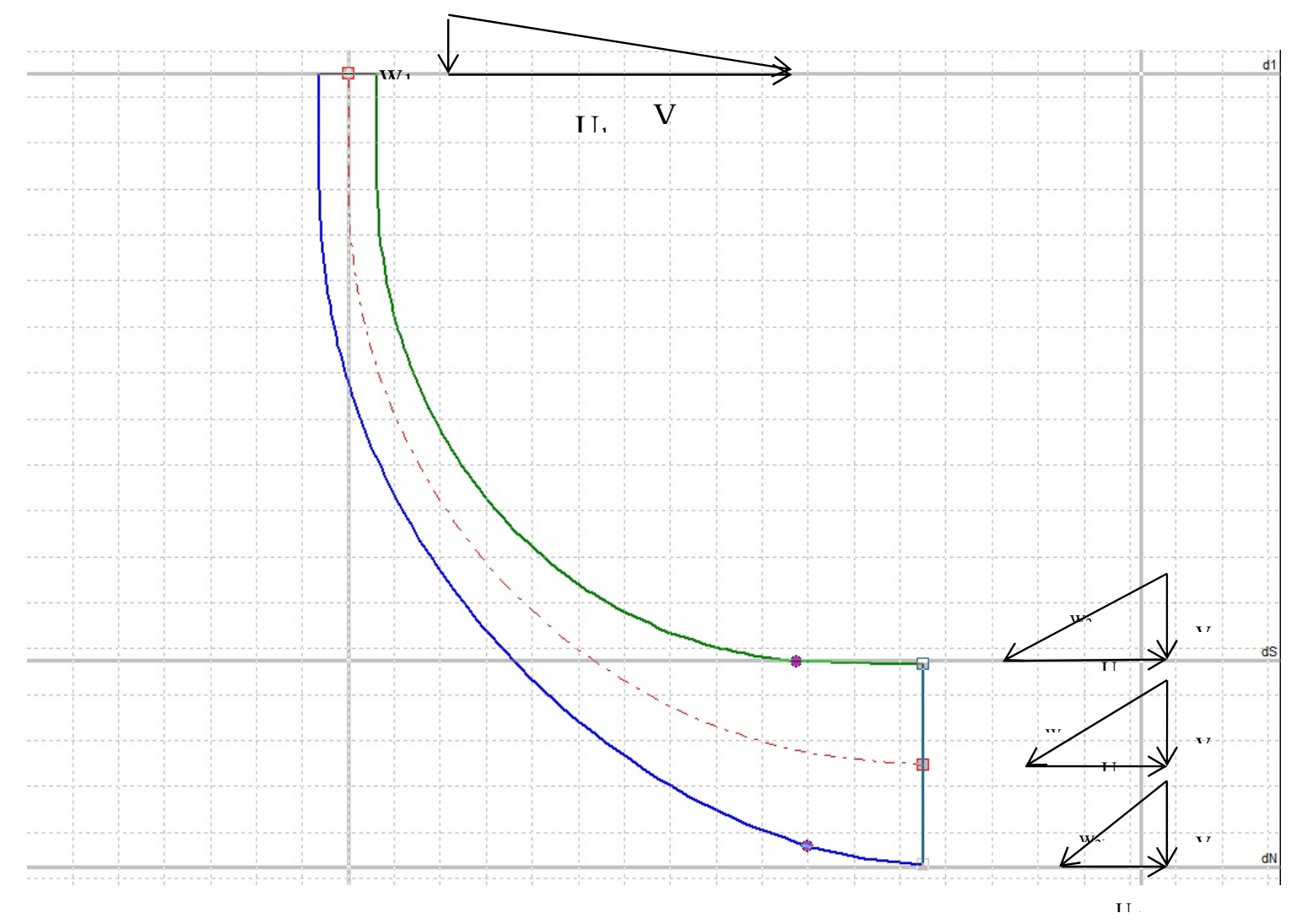

\subsection{Shape of the blades}

Once defined the thermodynamic conditions of the fluid entering and exiting the impeller through CAMEL-Pro, and the velocity triangles, diameters and blade heights in the inlet and outlet sections, we started the sizing of the blade profile. First, the mean line has to be defined: we chose to use a portion of straight line and an arc linked. 20 points as equidistant as possible are considered, (Fig. 12). The target was to determine the velocity triangles at each point, to calculate the height of the blade profile deriving the hub and shroud lines of the impeller. First, having the y coordinates of each point (corresponding to the distance of the point from the rotational axis), it is possible to calculate the rotational speed at each point. At this point, knowing the initial value $W_{l}$ and the final value $W_{2}$ of the relative velocity, a linearly increasing trend of $\mathrm{W}$ along the mean line of the blade has been assumed. Finally, the value of the angle $\beta$ at any point of the mean line has imposed. In this way we are able to calculate the meridian velocities, which are fundamental, to define of the height of the blade profile and the tangential speeds. For the distribution a trend shown in Fig.13 has been chosen. Assimilating the working fluid to perfect gas, to determine the density at any point, the temperatures and pressures at the same points are needed. For temperature a linear progression along the mean line (the rotor inlet temperature, pressure and density have been calculated from the degree of reaction, entering in the 
Mollier chart of R245fa) are adopted, while pressures were determined through the relationship between pressure and temperature in the case of the polytrophic expansion. The volumetric flow rate at each point is so defined. To calculate the height of the blade profile, initially the target area, the meridian velocity and $\delta=0.9$ have been set. We have obtained the value of the section area in function of blade height.

The points defining the hub and shroud lines were obtained respectively by subtracting and adding to the coordinates of the mean line, previously defined, the half-height of the blade profile in a direction perpendicular to the tangent to the curve.

Finally, to maintain a certain uniformity of the meridian velocity and a constant Euler work on the section, the blades necessary must be twisted. All data collected are reported in table 7 .

Figure 12: Straight line and points distance on it

Figure 13: meridian velocity trend
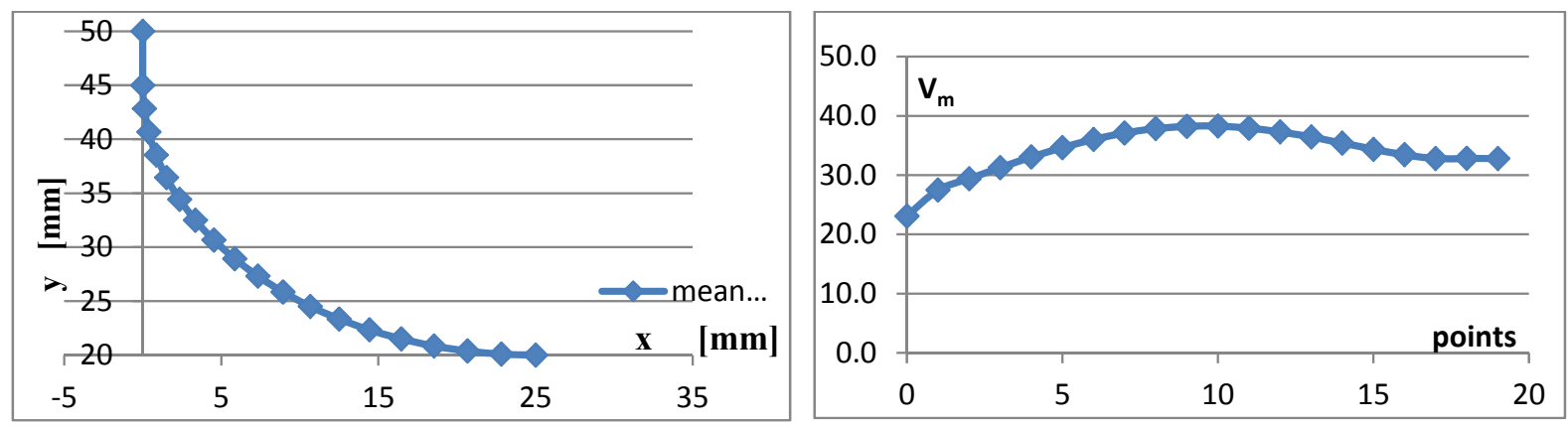

Table 7: Design procedure results

\begin{tabular}{|c|c|c|c|c|c|c|c|c|c|c|c|c|}
\hline \multicolumn{7}{|c|}{ HUB } & \multicolumn{6}{|c|}{ TIP } \\
\hline p. & $\begin{array}{c}\mathbf{V}_{\mathbf{t}} \\
{[\mathbf{m} / \mathbf{s}]}\end{array}$ & $\underset{[\mathbf{m} / \mathbf{s}]}{\mathbf{U}}$ & $\begin{array}{c}\mathbf{W} \\
{[\mathbf{m} / \mathbf{s}]}\end{array}$ & $\begin{array}{c}\mathrm{V} \\
{[\mathrm{m} / \mathrm{s}]}\end{array}$ & $\begin{array}{l}\boldsymbol{\beta} \\
{\left[{ }^{\circ}\right]}\end{array}$ & $\begin{array}{c}\boldsymbol{\alpha} \\
{\left[{ }^{\circ}\right]}\end{array}$ & $\begin{array}{c}\mathrm{V}_{\mathrm{t}} \\
{[\mathrm{m} / \mathrm{s}]}\end{array}$ & $\begin{array}{c}\mathbf{V} \\
{[\mathbf{m} / \mathbf{s}]}\end{array}$ & $\begin{array}{c}\mathbf{W} \\
{[\mathbf{m} / \mathbf{s}]}\end{array}$ & $\begin{array}{c}\mathbf{V} \\
{[\mathbf{m} / \mathbf{s}]}\end{array}$ & $\begin{array}{l}\boldsymbol{\beta} \\
\left.{ }^{\circ}\right]\end{array}$ & $\begin{array}{c}\boldsymbol{\alpha} \\
{\left[{ }^{\circ}\right]}\end{array}$ \\
\hline $\mathbf{0}$ & 131,3 & 131,3 & 23,1 & 133,3 & 90,0 & 10,0 & 131,3 & 131,3 & 23,1 & 133,3 & 90,0 & 10,0 \\
\hline 1 & 118,1 & 118,2 & 27,5 & 121,3 & 90,0 & 13,1 & 118,1 & 118,2 & 27,5 & 121,3 & 90,0 & 13,1 \\
\hline 2 & 112,7 & 112,2 & 29,4 & 116,5 & 91,1 & 14,6 & 112,1 & 112,7 & 29,4 & 115,9 & 88,8 & 14,7 \\
\hline 3 & 106,1 & 106,2 & 31,3 & 110,6 & 89,8 & 16,4 & 104,9 & 107,4 & 31,4 & 109,5 & 85,5 & 16,6 \\
\hline 4 & 98,8 & 100,3 & 33,1 & 104,2 & 87,5 & 18,5 & 97,0 & 102,1 & 33,4 & 102,5 & 81,3 & 18,8 \\
\hline 5 & 91,2 & 94,5 & 34,8 & 97,6 & 84,7 & 20,8 & 88,8 & 97,0 & 35,6 & 95,4 & 76,8 & 21,3 \\
\hline 6 & 83,3 & 88,8 & 36,4 & 90,8 & 81,4 & 23,4 & 80,4 & 92,1 & 37,9 & 88,1 & 72,0 & 24,1 \\
\hline 7 & 75,4 & 83,3 & 38,0 & 84,0 & 78,0 & 26,2 & 71,8 & 87,4 & 40,3 & 80,8 & 67,2 & 27,3 \\
\hline 8 & 67,3 & 78,0 & 39,3 & 77,2 & 74,2 & 29,4 & 63,1 & 83,1 & 42,8 & 73,6 & 62,2 & 31,0 \\
\hline 9 & 59,2 & 72,9 & 40,6 & 70,5 & 70,4 & 32,8 & 54,6 & 79,1 & 45,4 & 66,6 & 57,3 & 35,0 \\
\hline 10 & 51,4 & 68,0 & 41,7 & 64,1 & 66,6 & 36,7 & 46,3 & 75,5 & 48,2 & 60,1 & 52,7 & 39,6 \\
\hline 11 & 43,7 & 63,4 & 42,7 & 57,9 & 62,5 & 41,0 & 38,3 & 72,4 & 51,0 & 53,9 & 48,0 & 44,7 \\
\hline 12 & 36,4 & 59,1 & 43,7 & 52,1 & 58,7 & 45,7 & 30,8 & 69,7 & 53,9 & 48,4 & 43,8 & 50,4 \\
\hline 13 & 29,5 & 55,1 & 44,5 & 46,9 & 54,9 & 51,0 & 24,0 & 67,6 & 56,8 & 43,6 & 39,9 & 56,6 \\
\hline 14 & 23,0 & 51,4 & 45,4 & 42,2 & 51,3 & 57,0 & 17,9 & 66,0 & 59,7 & 39,7 & 36,4 & 63,2 \\
\hline 15 & 17,0 & 48,1 & 46,3 & 38,3 & 47,9 & 63,6 & 12,6 & 64,9 & 62,5 & 36,6 & 33,3 & 69,8 \\
\hline
\end{tabular}




\begin{tabular}{l|cccccccccccc}
\cline { 2 - 11 } $\mathbf{1 6}$ & 11,7 & 45,3 & 47,4 & 35,4 & 44,9 & 70,8 & 8,2 & 64,2 & 65,2 & 34,5 & 30,9 & 76,2 \\
$\mathbf{1 7}$ & 6,9 & 43,1 & 48,8 & 33,5 & 42,2 & 78,0 & 4,7 & 63,9 & 67,7 & 33,1 & 29,0 & 81,9 \\
$\mathbf{1 8}$ & 3,2 & 41,7 & 50,6 & 33,0 & 40,5 & 84,4 & 2,1 & 63,8 & 69,9 & 32,9 & 28,0 & 86,3 \\
$\mathbf{1 9}$ & 0,0 & 41,0 & 52,5 & 32,8 & 38,7 & 89,9 & 0,0 & 64,1 & 72,0 & 32,8 & 27,1 & 89,9 \\
\hline
\end{tabular}

\subsection{Number of blades}

In order to minimize losses but at the same time a well guided flow, the analytical equation for the number of blades imposes:

$$
Z_{\min }=2 \pi \operatorname{cotg}\left(\alpha_{1}\right)
$$

Where $\alpha_{l}$ is the angle between $V$ and $U$ at the leading edge. This trend is plotted in Fig. 15. At low values of $\alpha_{1}$, the equation gives a very high number of blades, in our case 36. A number of blades so high produces great friction losses, thus, Glassman suggests to calculate the minimum number of blades using the following empirical relationship :

$$
Z_{\min }=\frac{\pi}{30}\left(\alpha_{1}+20\right) \operatorname{cotg}\left(\alpha_{1}\right)
$$

Thanks to this relationship, the number of blades is fixed to 18 , but since the number of blades is always chosen equal to a prime number to avoid vibrations in coupling with the stator, the final result for $z_{p}$ is 19 . Actually, the number of blades should be corrected through the slip factor but in our case its influence can be neglected and then the number of blades does not change.

A 3D sketch of the obtained turbine blade is presented in Fig. 15.

$$
\sigma=1-\theta \frac{\pi \sin \beta_{2}}{\mathrm{Z}} \theta:(\text { blockage factor }=0.5-0.6)
$$

Figure 14: Number of blades vs $\alpha_{1}$ angle

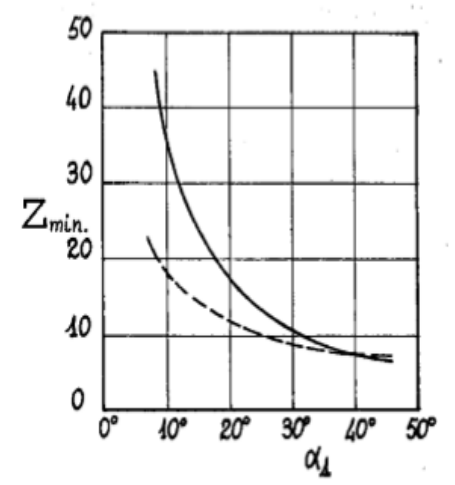


Figure 15: 3D sketch of turbine rotor

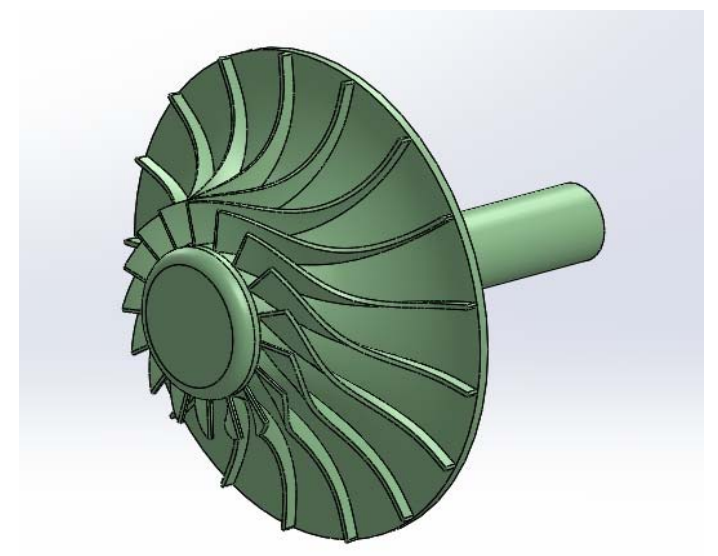

\section{Structural analysis and simulation: choice of material}

Through the SolidWorks [18] software, the simulation of the rotor for four different materials has been carried out. In table 8 the description and the characteristics of the four material investigated are reported.

Table 8: Investigated materials characterostics

\begin{tabular}{|c|c|c|c|c|c|}
\hline Material & Elastic modulus [Mpa] & $\begin{array}{c}\text { Yield } \\
{[\mathbf{M P a}]}\end{array}$ & $\begin{array}{c}\text { Displacement } \\
{[\mathbf{m m}]}\end{array}$ & Strain & $\begin{array}{c}\text { Von Mises } \\
{[\mathbf{M P a}]}\end{array}$ \\
\hline Molten carbon steel & 200000 & 248 & $3.36310^{-4}$ & $7.53610^{-5}$ & 18.1 \\
\hline Carbon steel & 210000 & 221 & $3.19510^{-4}$ & $6.82210^{-6}$ & 18.4 \\
\hline Chromium stainless steel & 200000 & 172 & $3.35410^{-4}$ & $7.16310^{-5}$ & 18.5 \\
\hline Steel alloy & 210000 & 620 & $3.15410^{-4}$ & $6.73510^{-5}$ & 18.2 \\
\hline
\end{tabular}

The material chosen after the simulations is carbon steel The same material will be used for shaft, stator and volute. On the software, centrifugal force has been set as main stress, setting the value of the rotational speed and the axis of rotation. In this first phase the contribution of the pressure drop has been neglected, and for "computational constrains" only single blade has been simulated. The analysis supply structural resistance to mechanical stress of the blade and the main characteristic of the blade behavior by:

- Von Mises stress (figure 16)

- Displacement (figure 17)

- Strain (figure 18)

Figure 16 shows the trend of value of Von Mises stress, located at the base of the blade with the rotor disk. In the case of the chosen material (carbon steel), the results obtained supply a value that is lower than the threshold value. 
Similar considerations can be done for the results reported in figure 17. Analyzing the displacement of the blade it is evident as it is located in the outlet section (in correspondence of $\mathrm{D}_{2}$ ), but still below the threshold.

Finally the map of strain. It is at each point (Figure 18) below the critical value.

These results confirm the validity of our choices. First of all, of the material (carbon steel), It can be noted as there are not structural problems, as we expected, because of the low rotational speed. Moreover there are not thermal problems because the maximum temperature is about $90{ }^{\circ} \mathrm{C}$ which the material can safely support, without any difficult.

Figure 16 : Von Mises stress

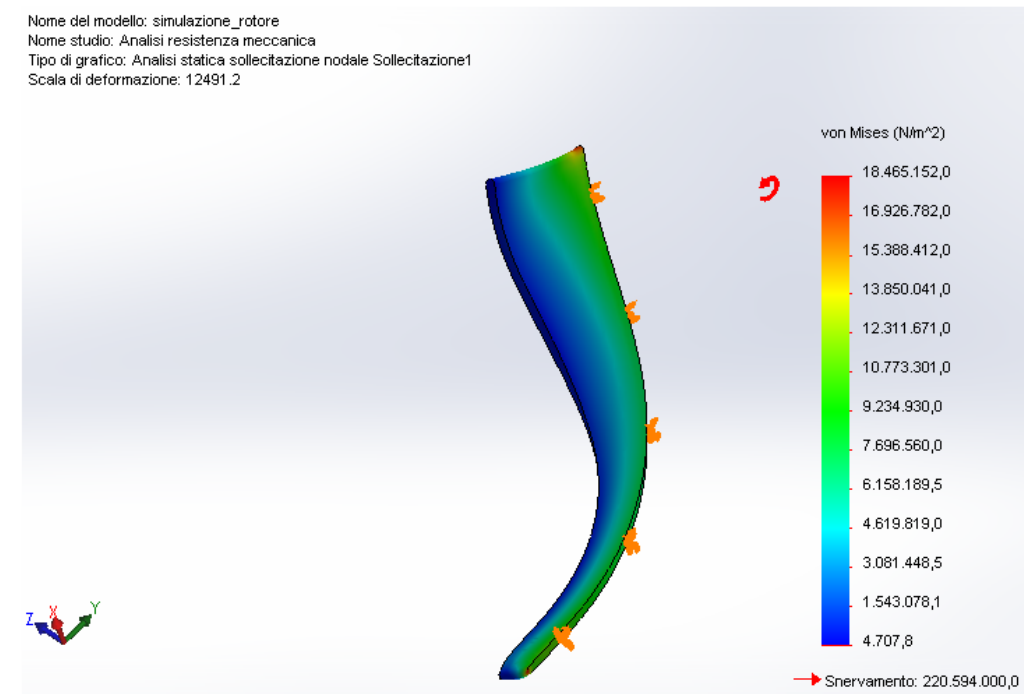

Figure 17 : Displacement
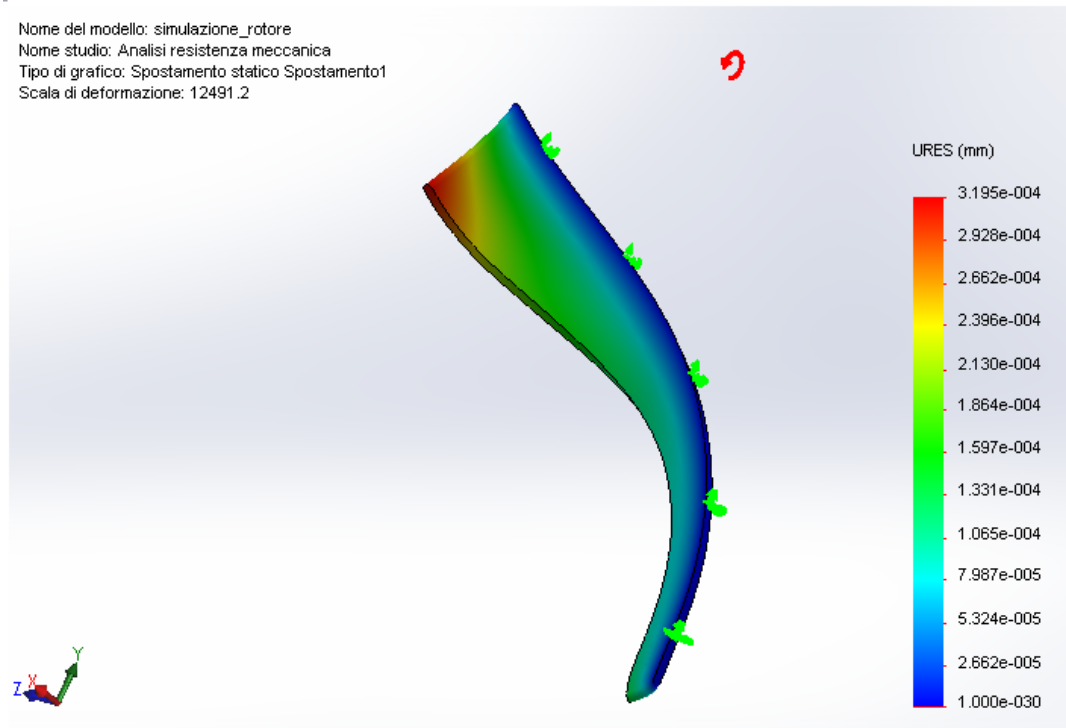
Figure 18 : Strain

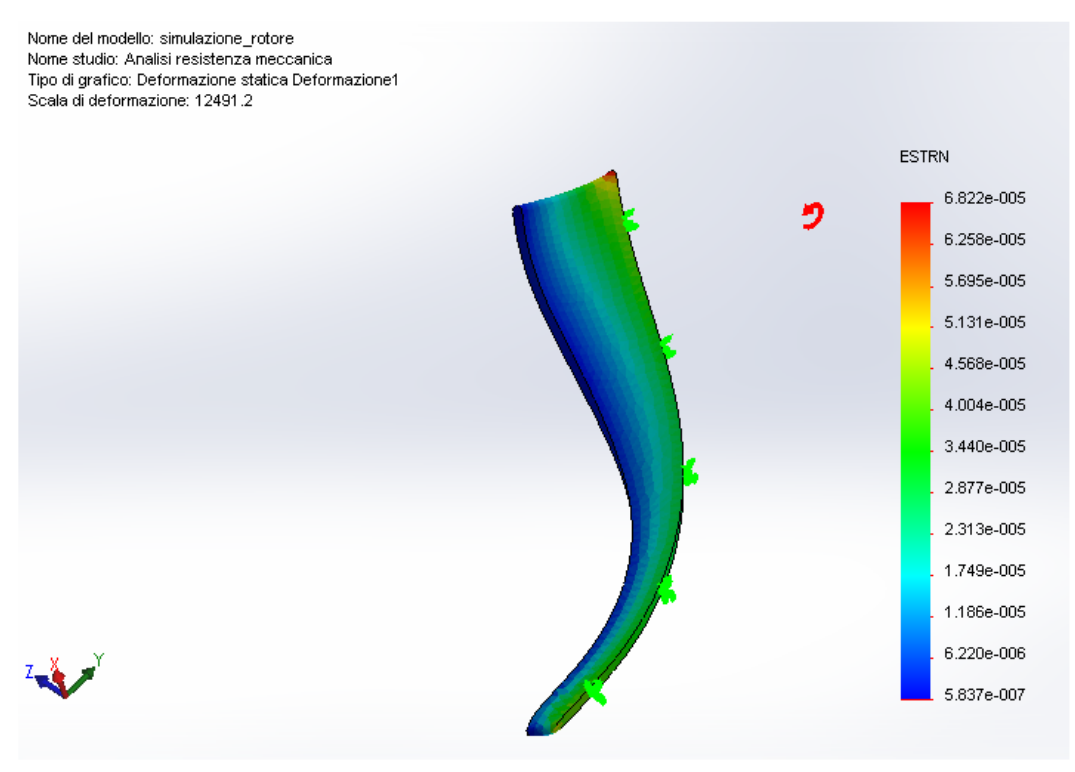

\section{Conclusions and future developments}

This paper presents the thermodynamic feasibility of an innovative Organic Rankine Cycle and a preliminary design of its main component, the expander.

The novelty lies in the choice of this component. The intention is to see if you can make this device, "breaking" the usual practice, that today uses volumetric expanders

The main challenge of the analysis are the imposed size and weight limitations that require a particular design. The procedure also presented quite a few problems, since the only references were those defined and described by Rohlik. Finally a preliminary design of the impeller has been provided.

At the same time, as previously described, a possible system layout has been analyzed and the requirements for a prototypal application investigated.

This simulation has been important both because it has provided feedback on the values of the expander and supply information on the nominal power of the system and about the behavior of the R245fa, as working fluid.

Further development of the study will include to complete the design procedure, including stator and volute, to supply a complete layout of the device, to perform other thermodynamics simulation with other organic fluids such as R134 to investigate by a thermodynamic study the super-heater and/or a pre-heater components and to study the interaction between components and the organic fluid.

And, finally, a market and cost analysis. All this data can be a valid support for the final step of the research, that is the realization of the prototypal ORC system.

\section{Nomenclature}

$\mathrm{d}, \quad$ diameter $[\mathrm{m}]$ 
h, specific enthalpy $[\mathrm{kJ} / \mathrm{kg}]$

L. work [J]

$\mathrm{p}$, Pressure $[\mathrm{kPa}]$

$\mathrm{R}_{\mathrm{p}} \quad$ degree of reaction

$\mathrm{T}, \quad$ Temperature [K]

$\mathrm{U}$, periferic velocity $[\mathrm{m} / \mathrm{s}]$

$\mathrm{V}, \quad$ absolute velocity $[\mathrm{m} / \mathrm{s}]$

$\mathrm{W}$, relative velocity $[\mathrm{m} / \mathrm{s}]$

$\rho, \quad$ density $\left[\mathrm{kg} / \mathrm{m}^{3}\right]$

$\delta$, blockage factor

$\varphi, \quad$ flow rate coefficient

$\psi, \quad$ load coefficient

\section{References}

1. T.C. Hung, T.Y. Shai, S.K. Wang, A review of organic rankine cycles (ORCs) for the recovery of low-grade waste heat, Energy, 22 (7) (1997) 661-667.

2. T.-C. Hung, Waste heat recovery of organic Rankine cycle using dry fluids, Energy Conversion and Management, 42 (5) (2001) 539-553.

3. N.B. Desai, S. Bandyopadhyay, Process integration of organic Rankine cycle, Energy, 34 (10) (2009) 1674-1686.

4. B.J. Hipólito-Valencia, E. Rubio-Castro, J.M. Ponce-Ortega, M. Serna-González, F. NápolesRivera, M.M. El-Halwagi, Optimal integration of organic Rankine cycles with industrial processes, Energy Conversion and Management, 73 (0) (2013) 285-302.

5. F.A. Al-Sulaiman, Exergy analysis of parabolic trough solar collectors integrated with combined steam and organic Rankine cycles, Energy Conversion and Management, 77 (0) (2014) 441-449.

6. R.S. El-Emam, I. Dincer, Exergy and exergoeconomic analyses and optimization of geothermal organic Rankine cycle, Applied Thermal Engineering, 59 (1-2) (2013) 435-444.

7. [C.O. Katsanos, D.T. Hountalas, E.G. Pariotis, Thermodynamic analysis of a Rankine cycle applied on a diesel truck engine using steam and organic medium, Energy Conversion and Management, 60 (0) (2012) 68-76

8. Roberto Capata, Enrico Sciubba, Claudia Toro, The gas turbine hybrid Vehicle LETHE@ at UDR1: the on-board innovative ORC energy recovery system - feasibility analysis, Proceedings of ASME IMECE2012, Houston, TX, USA November 2012

9. Bao J., Zhao L. A review of working fluid and expander selections for Organic Rankine Cycle, Renewable and Sustainable Energy Reviews 2013; 24: 325-342

10. Tian H., Shu G., Wei H., Liang X., Liu L. Fluids and parameters optimization for Organic Rankine Cycles (ORCs) used in exhaust heat recovery of Internal Combustion Engine (ICE), Energy 2012; 47: 125-136 
11. Lemmon EW, Huber ML, McLinden MO. NIST Standard Reference Database 23: Reference Fluid Thermodynamic and Transport Properties-REFPROP, Version 9.1. 2013

12. Kang S. H. Design and experimental study of ORC and radial turbine using R245fa working fluid, Energy 2012; 41: 514-524

13. Fiaschi D., Manfrida G., Maraschiello F., Thermo-fluid dynamics preliminary design of turboexpanders for ORC cycles, Applied Energy 2012; 97: 601-608

14. Declaye S, Quoilin S, Guillaume L, Lemort V. Experimental study on an open-drive scroll expander integrated into an ORC (Organic Rankine Cycle) system with R245fa as working fluid. Energy. 2013;55:173-83.

15. Qiu G, Liu H, Riffat S. Expanders for micro-CHP systems with organic Rankine cycle. Applied Thermal Engineering. 2011;31:3301-7

16. Amati V, Coccia A, Sciubba E, Toro C. CAMEL-Pro Users Manual, rev. 4. www.turbomachinery.it; 2010.

17. Rohlik H. L. Analytical determination of radial inflow turbine design geometry for maximum efficiency, NASA TN D-4384, 1968

18. SolidWork's User Guide, www.solidworks.it.

19.

(C) 2014 by the authors; licensee MDPI, Basel, Switzerland. This article is an open access article distributed under the terms and conditions of the Creative Commons Attribution license (http://creativecommons.org/licenses/by/3.0/). 